\title{
Seismic vulnerability of historical adobe buildings in the coast of Peru
}

\author{
C. Cuadra \\ Department of Architectural and Environment Systems, \\ Akita Prefectural University, Japan
}

\begin{abstract}
This paper attempts to describe the structural conditions of the historical adobe buildings that are located in the coast of Peru, which is a zone of high seismic activity. The seismicity of the zone is discussed through an earthquake hazard analysis and the importance of action towards the protection of heritage architecture is emphasized. It is noted that the state of general disrepair and the intrinsic weakness of the earthen constructions add to the seismic vulnerability of this kind of heritage architecture. Besides, the repair after actual damage or destruction from earthquakes, even when timely undertaken, may lead to alteration of the valuable originality of heritage structures, owing to the unavailability of materials or skill from the time of the original constructions. The need for initiatives towards preventive actions for protection from damages and prevention of collapse due to earthquake disasters appears quite evident.
\end{abstract}

Keywords: adobe constructions, earthquake hazard, seismic vulnerability, Peru, world heritage.

\section{Introduction}

The west coast of South America (which includes the coast of Peru) is affected by frequent earthquakes that are originated mainly by the tectonic interaction between the Nasca plate and the South American plate. Protection of life and property from earthquake disasters has been the subject of major emphasis in engineering research and practice in this region. However, there seems to be little effort made to evaluate the vulnerability of heritage architecture to earthquake disasters and in general to natural disasters. 
In the coast of Peru, which presents a high seismic hazard level, many historical sites are located, and the constructions are mainly made of adobe or sun-dry bricks. It is well known that earthen constructions are in general weak structures to resist earthquake actions. Recent earthquakes that occurred in Peru, such as the Pisco earthquake of the year 2007, illustrate this situation. Moreover, the local economy makes it impossible to pay attention to cultural heritage in the aftermath. Therefore, the constant disrepair of the heritage architecture and the lack of research on the hazard, resistance and strength of historical buildings make the vulnerability of these constructions critical.

Earthquake disaster is not the only hazard that affects the vulnerability of historical adobe buildings located in the coast of Peru; there are also other kinds of natural disasters, such as drought, floods, sand storms, etc. On the other hand, in the urban areas, these historical buildings are affected by the invasion of people that construct houses in reserved zones or people that use part of the structure or materials to construct their houses.

\section{Seismic hazard of the coast of Peru}

The west coast of South America is affected by frequent earthquakes, originating mainly from tectonic interaction between the Nasca plate and the South American plate. The Peruvian Institute of Geophysics (IGP) has published the catalogue of historical earthquakes in this region, consisting of information from the year 1471. Old records of this earthquake catalogue have information of probable magnitude and estimated location inferred from historical reports on damages in affected zones. Moreover, earlier records prior to instrumental measurement cannot be expected to be representative of the actual distribution of hazard, since at earlier times only earthquakes occurring around populated areas seem to have been reported. If only records with complete information of location, magnitude, depth, etc are selected, the distribution of these instrumental recorded earthquakes appears as can be observed in Figure 1. It can be noted that there is a concentration of epicentres along the coastline. Also it can be observed that the southern part of Peru presents more activity than the north and central parts. To analyze the nature of earthquakes in the northern zone, the central zone and the southern zone, sections that show the earthquake distribution in elevation were constructed. The location of these sections are indicated in Figure 1 as section A-A for the north part, section B-B for the central part and section C-C for the south part of Peru. In all cases, earthquakes located inside a band of 200 $\mathrm{km}$ with the centre at the correspondent section line were considered.

Figure 2 shows the distribution of earthquakes in elevation for each section described in the previous paragraph. Although the distribution pattern presents the same tendency for each zone with shallow earthquakes near the coast and deeper inland earthquakes, the depth distribution and amount of earthquakes for each zone are quite different.

Section A-A shows the shallow earthquake distribution near the coast. The concentration of epicentres at focal depth from $100 \mathrm{~km}$ to $200 \mathrm{~km}$ can also be observed here. 


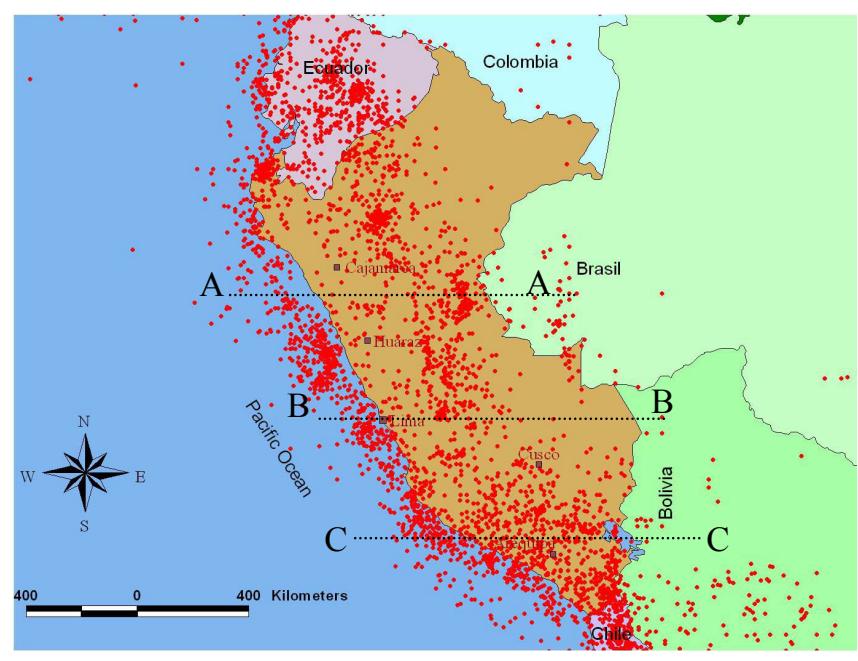

Figure 1: $\quad$ Earthquake distribution near the coast of Peru.

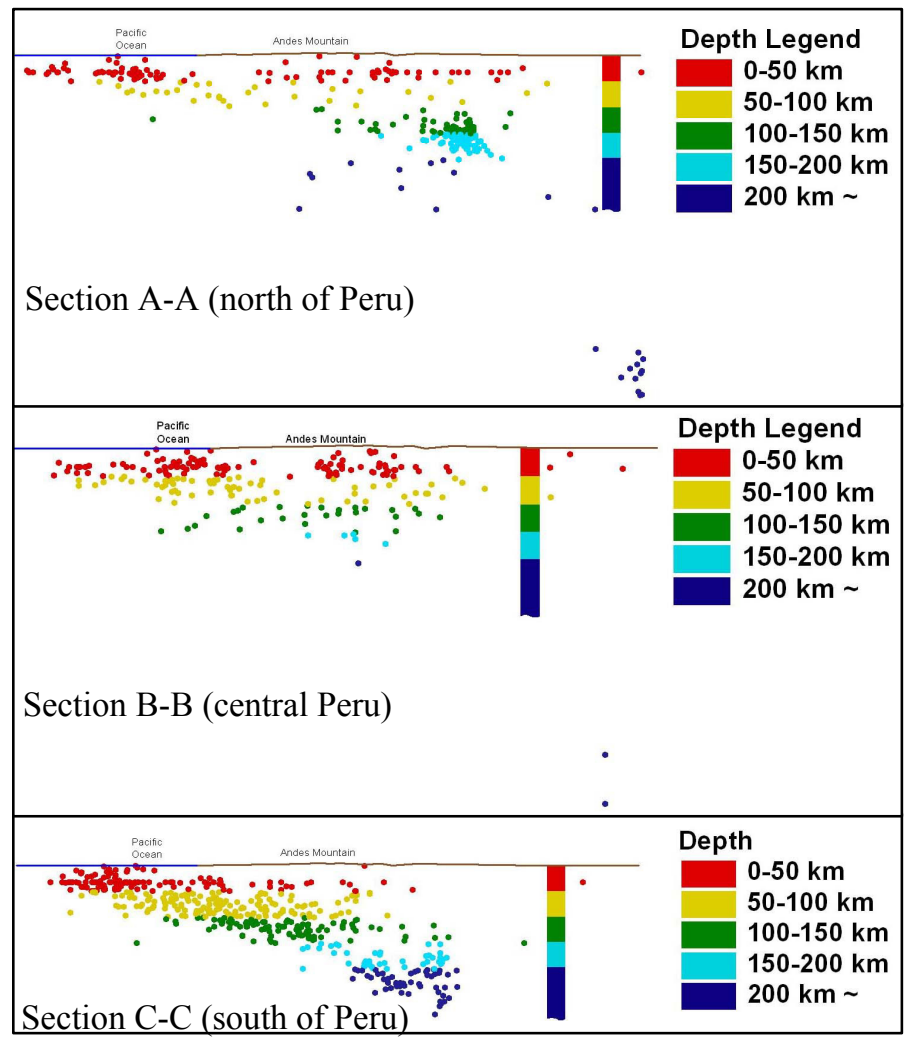

Figure 2: Distribution of earthquakes in elevation. 
Additionally, the concentration of deep epicentres is observed in the zone of the Amazon jungle (east part) with depths of the order of $500 \mathrm{~km}$.

In the section B-B the distribution of the earthquakes shows that in this zone the earthquakes have less than $200 \mathrm{~km}$ of depth. The shallow earthquakes near the coast are closer to the coastline, which means that the epicentres are closer to inland cities.

The section $\mathrm{C}-\mathrm{C}$ shows more clearly the typical earthquake distribution of the subduction action of the marine plate, with deeper inland earthquakes. It can be noted that the number of earthquakes is larger in comparison with the north and central part of Peru.

Seismic hazard analysis for representative sites of the Andean region of Peru (Cusco city), and the coast of Peru (Lima city) was performed by Cuadra et al [3] and are shown in Figure 3. Hazard curve for Los Angeles city is included for comparison. Results of the probabilistic seismic hazard analysis can also be expressed in terms of the return period shown in Figure 3, where peak ground acceleration (PGA) for different return periods with $10 \%$ probability of exceedance are plotted. It may be noted that the PGA for 100 year return period is around $0.25 \mathrm{~g}$ for the considered Andean region and for Lima (Coast of Peru) the PGA is $0.5 \mathrm{~g}$. This higher level of peak acceleration may produce failure in buildings in general and the situation become critical for weak material like adobe constructions. In addition, the PGA levels in Figure 3 represents rock or stiff soil conditions, while the actual level of shaking depends on local site conditions at specific heritage sites where the local site amplifications and other effects may be important.
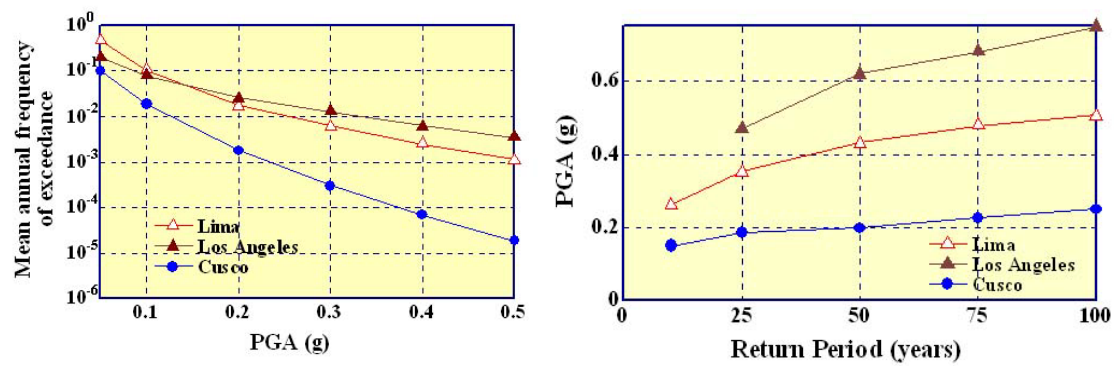

Figure 3: Hazard curve and PGA versus return period for representative sites.

\section{Historical sites in the coast of Peru}

Peru has many sites of cultural and natural heritage reflecting the pre-Inca era, Inca era as well as the subsequent era following Spaniard conquistadors in the $17^{\text {th }}$ century. The distribution of these heritages can be observed in Figure 4 and includes the world heritages declared by UNESCO which are marked by circles. Of the ten Peruvian heritage sites in the UNESCO world heritage list, six are 
considered cultural and two are considered natural. The remaining two are considered mixed category, meaning that the sites reflect the cultural as well as the natural heritage. Additionally to this UNESCO list, other architectural heritages located in the coast of Peru are included in Figure 4 and are marked by triangles. These selected architectural heritages correspond to structures made of adobe and are describe in the following sections.

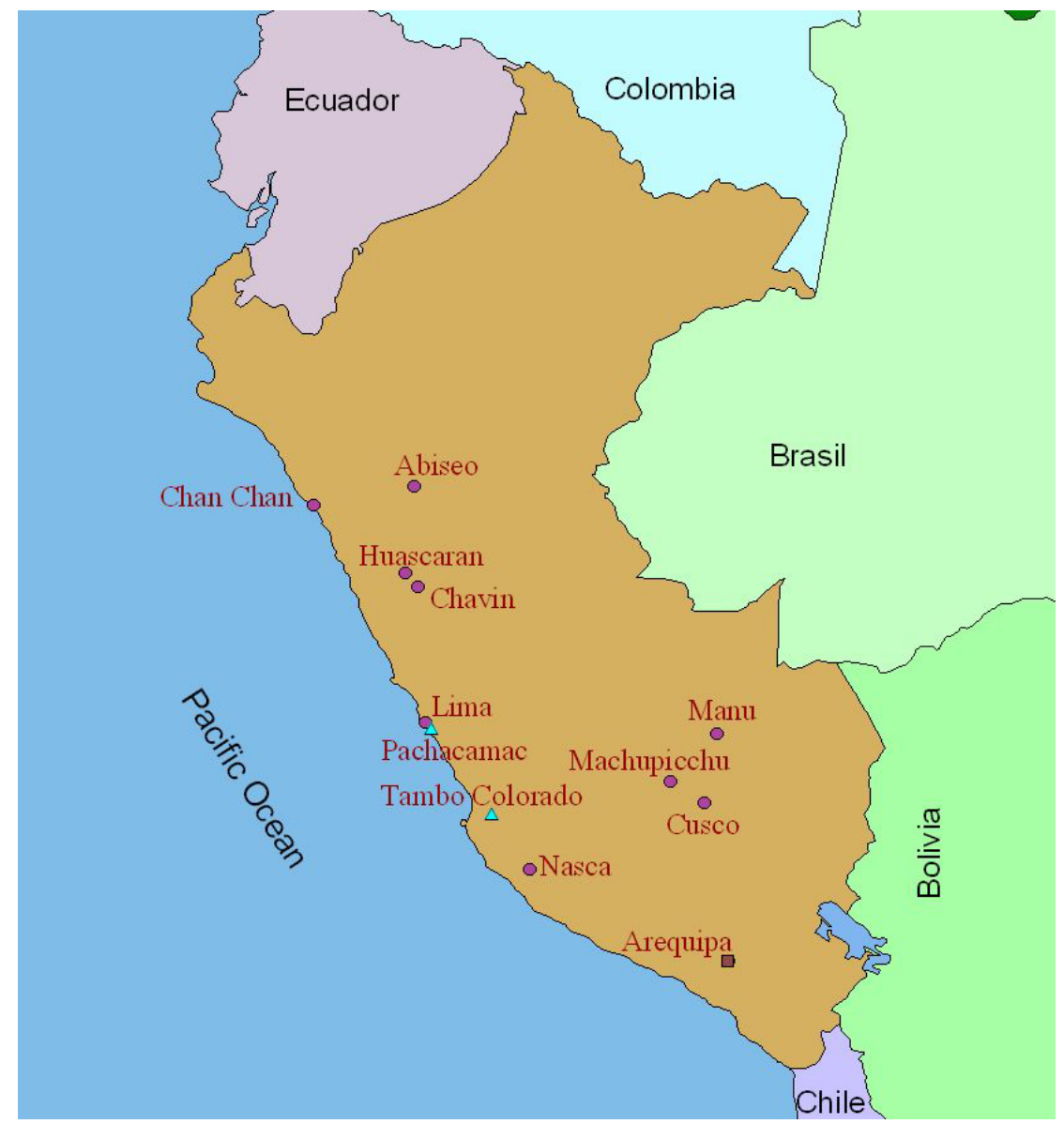

Figure 4: Peruvian world heritages distribution.

\subsection{Chan Chan archaeological zone}

Chan Chan is considered the largest old city of South America that was made of adobe. Chan Chan was the capital of a pre-Inca kingdom of Chimu. The remains of the city can be found in nine parts that are considered separated units or palaces because only around these places can be appreciated remarkable constructions. In Figure 5 some views of adobe constructions can be observed. 

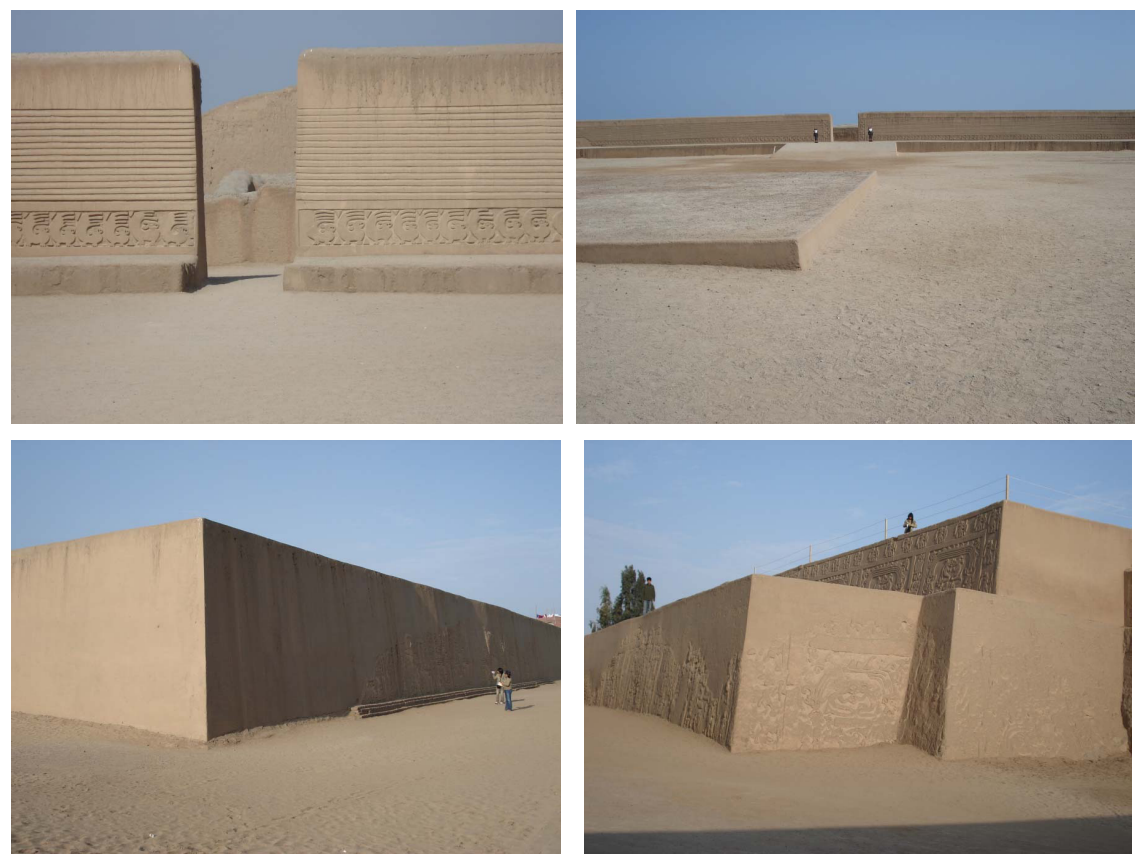

Figure 5: Some views of Chan Chan adobe city.

The adobe constructions are quickly damaged by natural erosion due to the air, salt, humidity and rain and they require continuous conservation efforts. This zone is also subjected to the impact of El Nino current which affects climate world-wide. Some years like 1983 and 1998 this phenomenon was unusually strong, leading to torrential rain and flooding. As was shown previously the seismic activity in this north part of Peru are smaller in comparison to the southern and central parts. However, historical earthquakes distribution and hazard analysis shown that this area is not free of earthquakes and on the contrary occurrence of rarely earthquakes could strike and damage earthen structures like Chan Chan.

\subsection{Archaeological complex of Pachacamac}

This complex was one of the main centres of religious cult, an oracle centre of ancient civilization in the central coast of Peru. It is a pre-Inca heritage which origins date from 200 a. c. It is believed that one of the deities of this temple was the god of earthquakes. Their constructions are made of adobe which present condition shows the fragility of this kind of material to the action of natural hazards. Figure 6 shows some view of the Pachacamac complex. The buildings in general are affected by the erosion due to the sand and also by the movement of the sand dunes that in some cases has destroyed and cover completely the buildings. It is difficult to infer the action of past earthquakes because the 
damage condition of the building could be the result of the action of earthquakes and the lack of appropriate maintenance. Another hazard to this complex becomes the rapidly development of the urban area near the complex that affect not only the landscape of the zone but the architecture heritage itself since construction materials are obtained from the historical place.
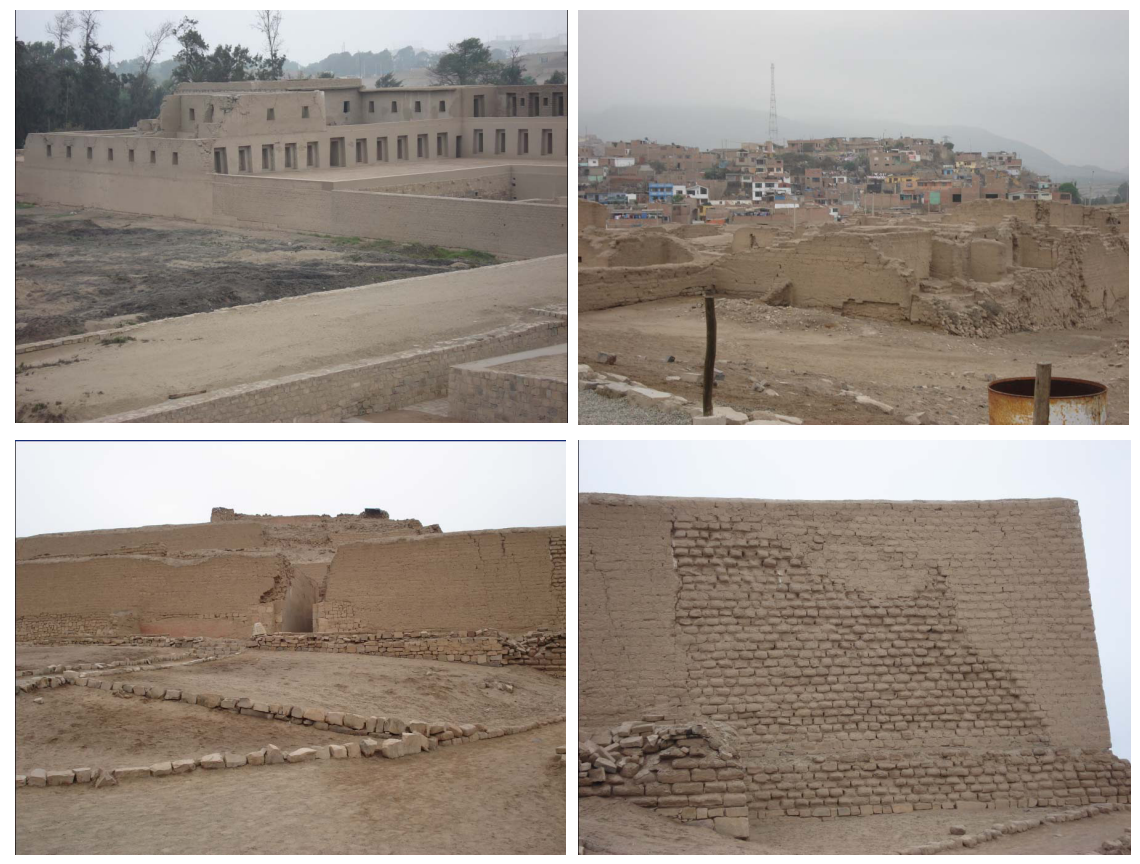

Figure 6: Some views of Pachacamac archaeological complex.

\subsection{Tambo Colorado}

It is believed that Tambo Colorado was one of the administrative centres of the Inca Empire. It is strategically located at the entrance to the Pisco valley, just 35 $\mathrm{km}$ inland from the port city of Pisco on the southern coast of Peru, and dominates access to the Inca road leading to the highlands and eventually to Cusco. All constructions are made of adobe and some of them have a coloured plaster with horizontal, alternating, ribbons of white, red and yellow. During the recent earthquake of Pisco of July 2007 many walls were affected and some of them fall down producing not only the failure of the structure itself but also the destruction of the coloured plaster. Some of these damages can be appreciated in Figure 7. In this case, together with the seismic vulnerability analysis it is necessary to analyze the plaster material to try to reconstruct the painted walls. It is obvious that it also has suffered considerable deterioration and damage during the years and urgent conservation measures are required to preserve this monument. 

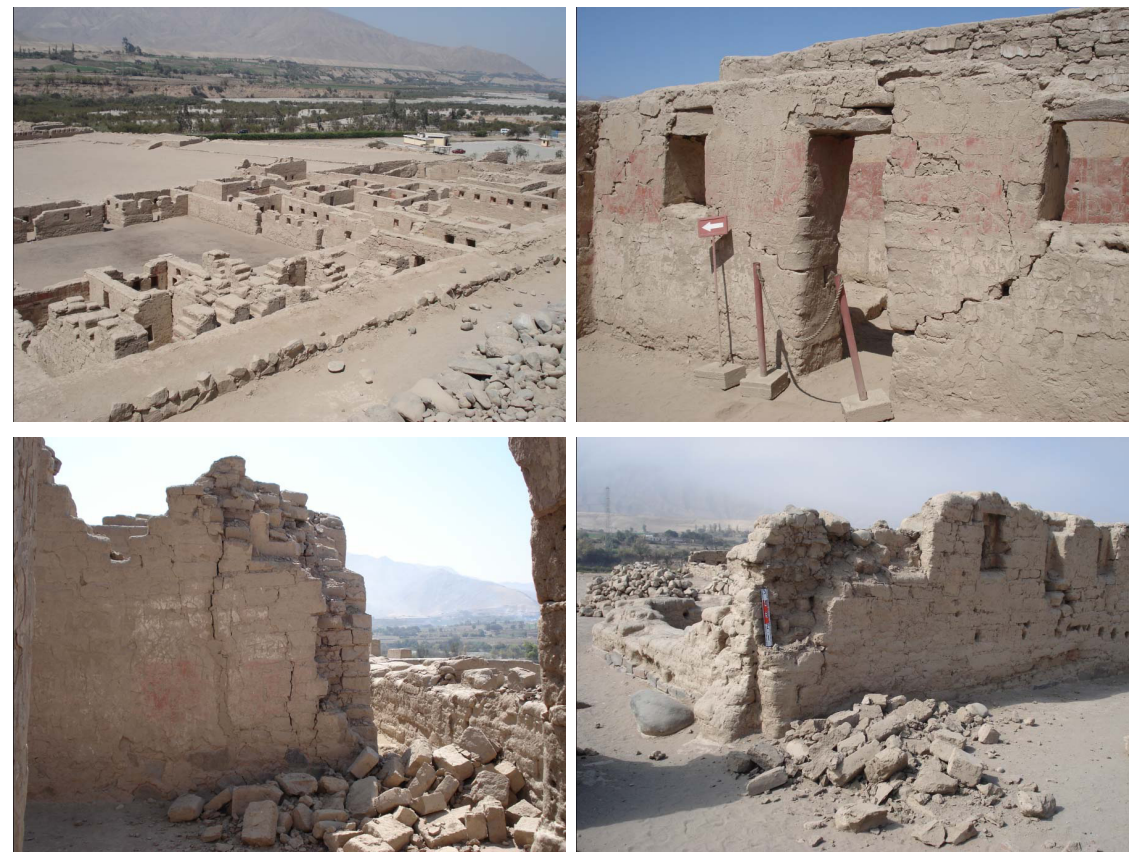

Figure 7: $\quad$ Some views of Tambo Colorado affected by earthquake motion.

\section{Conclusions}

Vulnerability of heritage architecture made of adobe and located in the coast of Peru was discussed. The heritage architecture is exposed to the action of earthquakes as well as another kind of natural hazards and risk emanating from human activity. The adobe heritage architecture is mostly in a state of disrepair and therefore the seismic risk and other kind of risks are particularly acute. The discussion of earthquake hazard to which heritage architecture in the coast of Peru are subjected and the description of the state or structural condition of the buildings, provides an overview of the challenges involved in protecting the heritage architecture made of adobe.

\section{References}

[1] C. Cuadra, Y. Sato, J. Tokeshi, H. Kanno, J. Ogawa, M. B. Karkee \& J. Rojas. Evaluation of the dynamic characteristics of typical Inca heritage structures in Machupicchu. Ninth International Conference on Structural Studies, Repairs and Maintenance of Heritage Architecture, STREMAH IX, Malta, Jun. 2005, pp. 237-244.

[2] M. B. Karkee, C. Cuadra, \& L. Sunuwar. The challenges of protecting heritage architecture in developing countries from earthquake disasters. 
Ninth International Conference on Structural Studies, Repairs and Maintenance of Heritage Architecture, STREMAH IX, Malta, Jun. 2005, pp. 407-419.

[3] C. Cuadra, M.B. Karkee, J. Ogawa, and J. Rojas. An evaluation of earthquake risk to Inca's historical constructions. Proceedings of the 13th World Conference on Earthquake Engineering, Vancouver, B.C., Canada, August 1-6, 2004, CD-ROM Paper No. 150.

[4] Sudhir R. Shrestha, Madan B. Karkee, Carlos H. Cuadra, Juan C. Tokeshi and S. N. Miller. Preliminary study for evaluation of earthquake risk to the historical structures in Kathmandu valley (Nepal). Proceedings of the 13th World Conference on Earthquake Engineering, Vancouver, B.C., Canada, August 1-6, 2004, CD-ROM Paper No. 172.

[5] J. Ogawa, C. Cuadra, M.B. Karkee, and J. Rojas. A study on seismic vulnerability of Inca's constructions. Proceedings of the 4th International Conference on Computer Simulation in Risk Analysis and Hazard Mitigation. Risk Analysis IV, Rhodes, Greece 2004, pp 3-12.

[6] C. Cuadra, M.B. Karkee, J. Ogawa, and J. Rojas. Preliminary investigation of earthquake risk to Inca's architectural heritage. Proceedings of the Fourth International Conference of Earthquake Resistant Engineering Structures, Ancona, Italy 2003, pp. 167-176.

[7] K. R. Wright and A. Valencia. Machu Picchu: A Civil Engineering Marvel. American Society of Civil Engineers ASCE PRESS, Reston Virginia, 2000.

[8] Sunuwar, L., Karkee, M., Tokeshi, J., and Cuadra, C. Applications of GIS in Probabilistic Seismic Hazard Analysis of Urban Areas. Proc. Of the Fourth International Conference of Earthquake Engineering and Seismology, Tehran, Iran, 2003.

[9] Thiel, C. Earthquake Damageability Criteria for Due Diligence Investigations. The Structural Design of Tall Buildings, 11, pp 233-263. 